\title{
Identification of Balanced and Unbalanced Complex Chromosomal Rearrangement Involving Chromosomes 1,11 , and 15
}

\author{
Farzane Vafaeie ${ }^{1}$, Masoume Ale Rasoul ${ }^{1,2}$, Maryam Rahnama ${ }^{1}$, Majid Mojarrad ${ }^{1,2,3}$ \\ 1. Medical Genetics Laboratory, Genetic Foundation of Khorasan Razavi, Mashhad, IRN 2. Department of Medical \\ Genetics, Mashhad University of Medical Sciences, Mashhad, IRN 3. Genetic Research Center, Faculty of Medicine, \\ Mashhad University of Medical Sciences, Mashhad, IRN
}

Corresponding author: Majid Mojarrad, majidmojarrad12@gmail.com

\begin{abstract}
Chromosomal abnormalities are the common genetic factors that significantly impact fertility, miscarriage possibility and abnormal offspring with unbalanced karyotype. Complex chromosomal rearrangements (CCRs) refer to structural rearrangements which involve more than two breakpoints and often more than two chromosomes. According to the mode of transmission, they can be either familial or de novo rearrangements.

Here we report a complex chromosomal rearrangement leading to intellectual disability, speech delay and multiple dysmorphic features, including cleft lip and inguinal hernia. Proband karyotype shows 46,XY,ins $(1:: 11)$ (q42 $\rightarrow$ qter::q25) compatible to partial trisomy $1 \mathrm{q} 42 \rightarrow \mathrm{qter}$, while the karyotype of his mother was $45, \mathrm{XX}$, ins $(1:: 15)(\mathrm{q} 42 ; \mathrm{q} 11.1 \rightarrow \mathrm{qter}), \mathrm{t}(1 ; 11)(\mathrm{q} 42, \mathrm{q} 25)$ compatible to apparently normal female phenotype.
\end{abstract}

Categories: Family/General Practice, Genetics, Other

Keywords: complex chromosomal rearrangements, partial trisomy, karyotype analysis, recurrent abortion, $\mathrm{g}$ banding analysis

\section{Introduction}

Complex chromosomal rearrangements (CCRs) refer to structural rearrangements which include more than two non-homologous chromosomes [1]. There are various classifications of CCRs based on the number of chromosomal breaks, the mode of transmission, balanced or unbalanced translocation, and the way of exchanging between three chromosomes to highly complex translocation [2].

Review began 06/16/2021 Review ended 06/23/2021 Published 07/04/2021

\section{○ Copyright 2021}

Vafaeie et al. This is an open access article distributed under the terms of the Creative Commons Attribution License CC-BY 4.0., which permits unrestricted use, distribution, and reproduction in any medium, provided the original author and source are credited.
Apparently, balanced CCRs carriers have a normal phenotype but the number of chromosomes and the number of breakpoints involved can vary greatly giving a variety of possible gametes. CCRs carriers are at a dramatically higher risk for infertility, recurrent abortions and abnormal offspring in comparison with classic translocations due to either malsegregation or recombination [3]. Most of familial CCRs are transmitted predominately through female carriers of balanced CCRs. In contrast, males balanced CCRs are often subfertile or sterile due to their chromosomes behavior during spermatogenesis [4].

Pedigree study and genetic testing, including karyotype analysis, are essential for genetic counseling of CCRs carriers [5]. Karyotype analysis is known as the gold standard method for prenatal cytogenetic diagnosis, including numerical and structural chromosomal aberrations. Partial aneuploidies in the offspring due to parental balanced chromosomal rearrangements can result in multiple congenital anomalies, intellectual disability, and other numerous dysmorphic features related to the size and origin of the involved segment [6]. Here, we report a case of 1q partial trisomy inherited from a carrier of CCR involving chromosomes 1, 11 and 15. Trisomy of the long arm of chromosome 1 is a rare chromosomal abnormality resulting from a parental balanced translocation. The clinical phenotypes of partial trisomy 1q syndrome are extremely diverse based on the location of breakpoints on chromosome 1 . However, the major symptoms include short stature, multiple minor anomalies, and intellectual disability [7, 8].

\section{Case Presentation}

Our patient was 7-year-old boy with multiple congenital anomaly and intellectual disability. He was the first child of a non-consanguineous couple. He was born at 33 weeks of gestation with a birth weight was $2100 \mathrm{~g}$. His length was $45 \mathrm{~cm}$ and head circumference was $38 \mathrm{~cm}$. Delivery was performed by cesarean section because of fetal arrhythmia. The infant could not suck and was fed with breast milk through a gastric tube for one week. The patient was referred to a genetic counseling center with a clinical history of intellectual disability and speech delay. In a primary clinical evaluation, he had multiple dysmorphic features including cleft lip (repaired by surgery), inguinal hernia, macrocephaly and a long face with a prominent forehead (Figure 1). The proband's mother had one pregnancy loss before 20th weeks of gestation and infertility for five years. There was no family history of miscarriages or genetic disorders. Her age at menarche was 14 years, and she had regular menstrual cycles. Ultrasound imaging revealed a normal uterus and ovaries. 


\section{Cureus}

According to patient clinical manifestations and presence of infertility and abortion, cytogenetic analysis was performed.

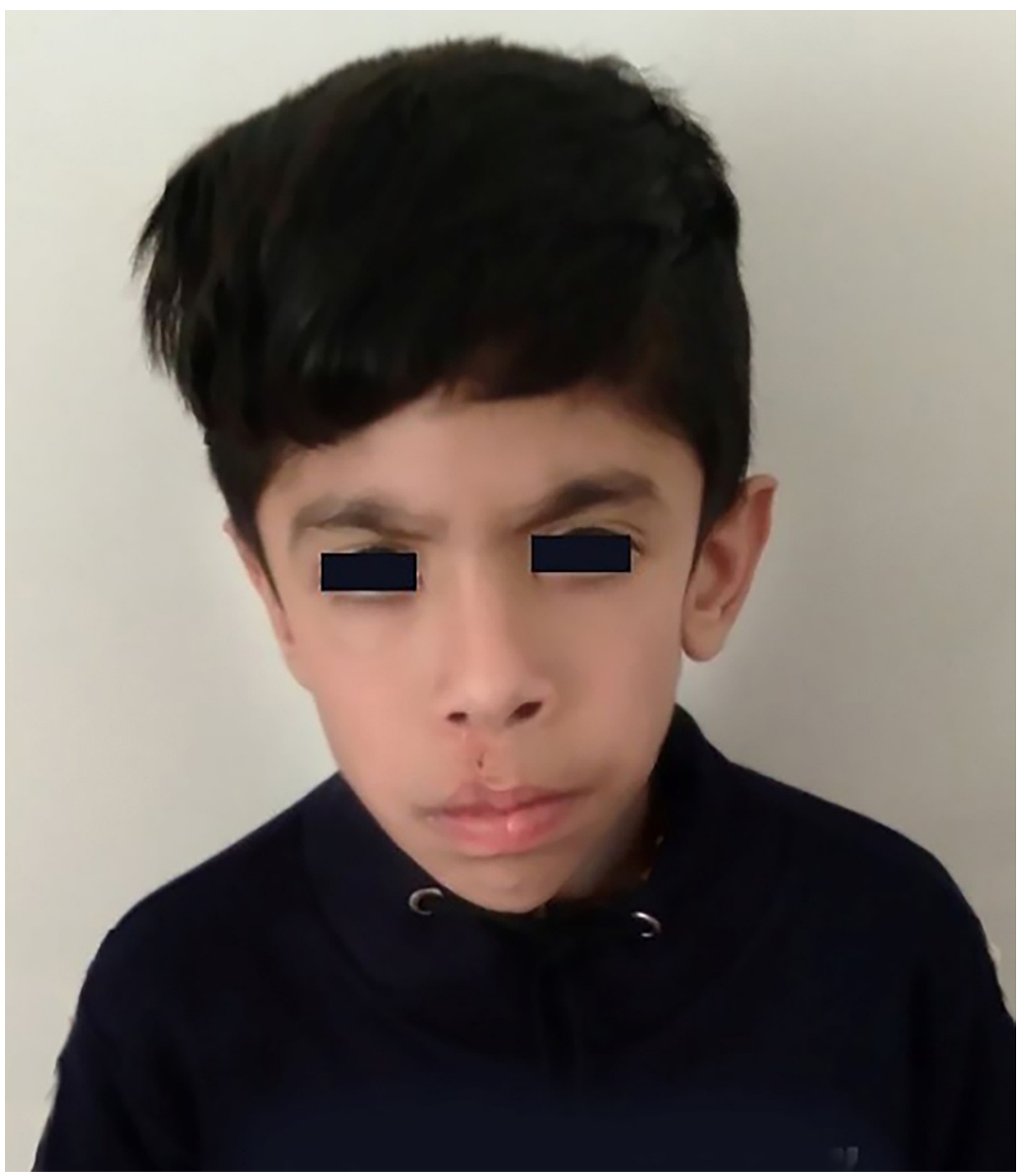

\section{FIGURE 1: The proband image at the age of 7, showing facial dysmorphisms including cleft lip and long face with a prominent forehead and triangular face.}

After taking informed consent from parents, peripheral blood sample from the proband and his parents was collected. Blood cells were cultured using RPMI 1640 . The blood cultures were incubated at $37^{\circ} \mathrm{C}$ for 4 days, the cell divisions were arrested in metaphases by adding colchicine $40 \mu \mathrm{M}$ final concentration for 30 minutes before harvesting the lymphocytes. RBC were lysed using hypotonic $0.075 \mathrm{M} \mathrm{KCl}$ solution treatment for 30 minutes. The samples were fixed in a solution of 3:1 methanol-acetic acid and spread in microscopic slides. Karyotype analysis in a light microscope was carried out on G-banded chromosomes. Cytogenetic analysis of the patient's prometaphase chromosomes was done by using GenAsis software. Karyotype analysis of the proband showed a structurally abnormal unbalanced karyotype. An extra unknown chromosomal fragment was detected on chromosome 11q (Figure 2). The proband's father's karyotype was normal but the karyotype analysis of the mother revealed apparently balanced translocation involving the long arm of chromosome 1 , the long arm of chromosome 11 and whole chromosome 15 at breakpoints 1q42, 11q22, and 15 q11 respectively (Figure 3). 


\section{Cureus}
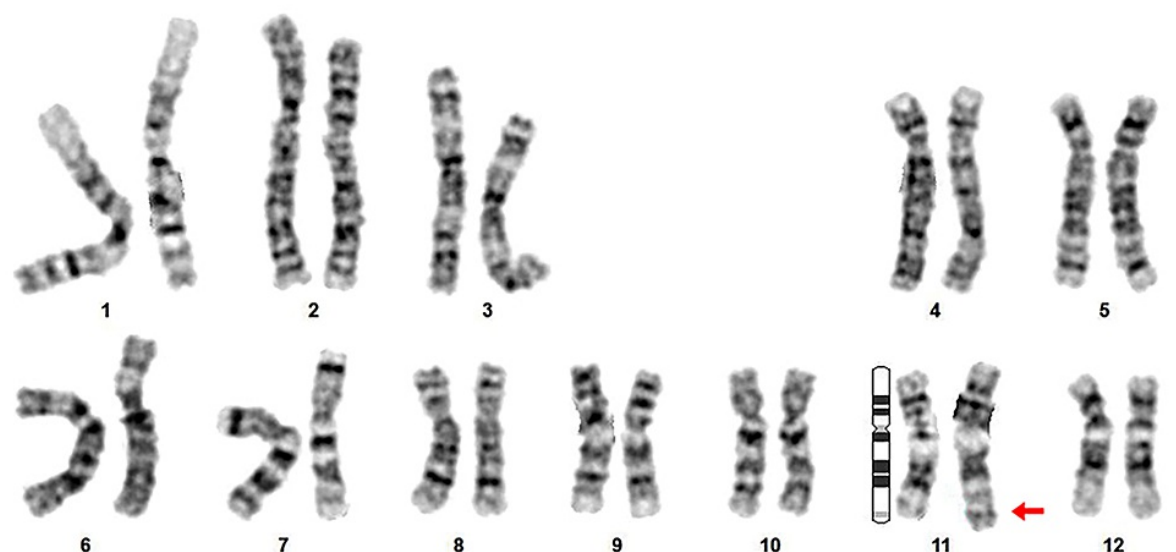

8

9

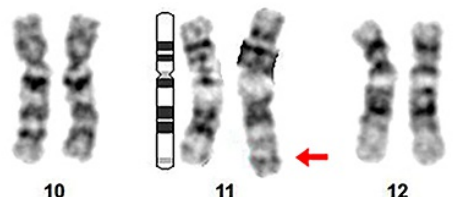

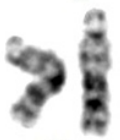

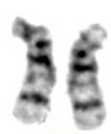

14
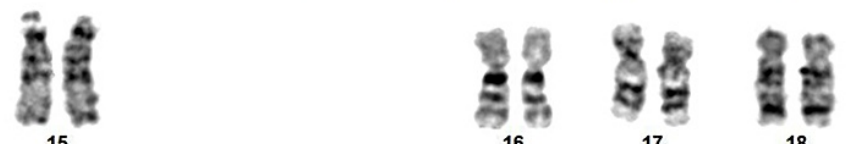

18
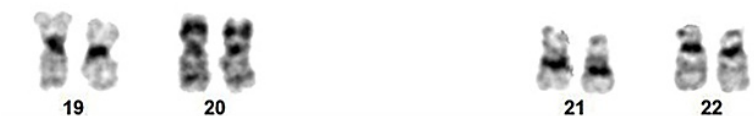

FIGURE 2: Chromosomal analysis of proband with familial insertion inherited from the mother. G-banding method at $\mathbf{6 5 0}$ bands per haploid on 50 spreads was performed. 


\section{Cureus}

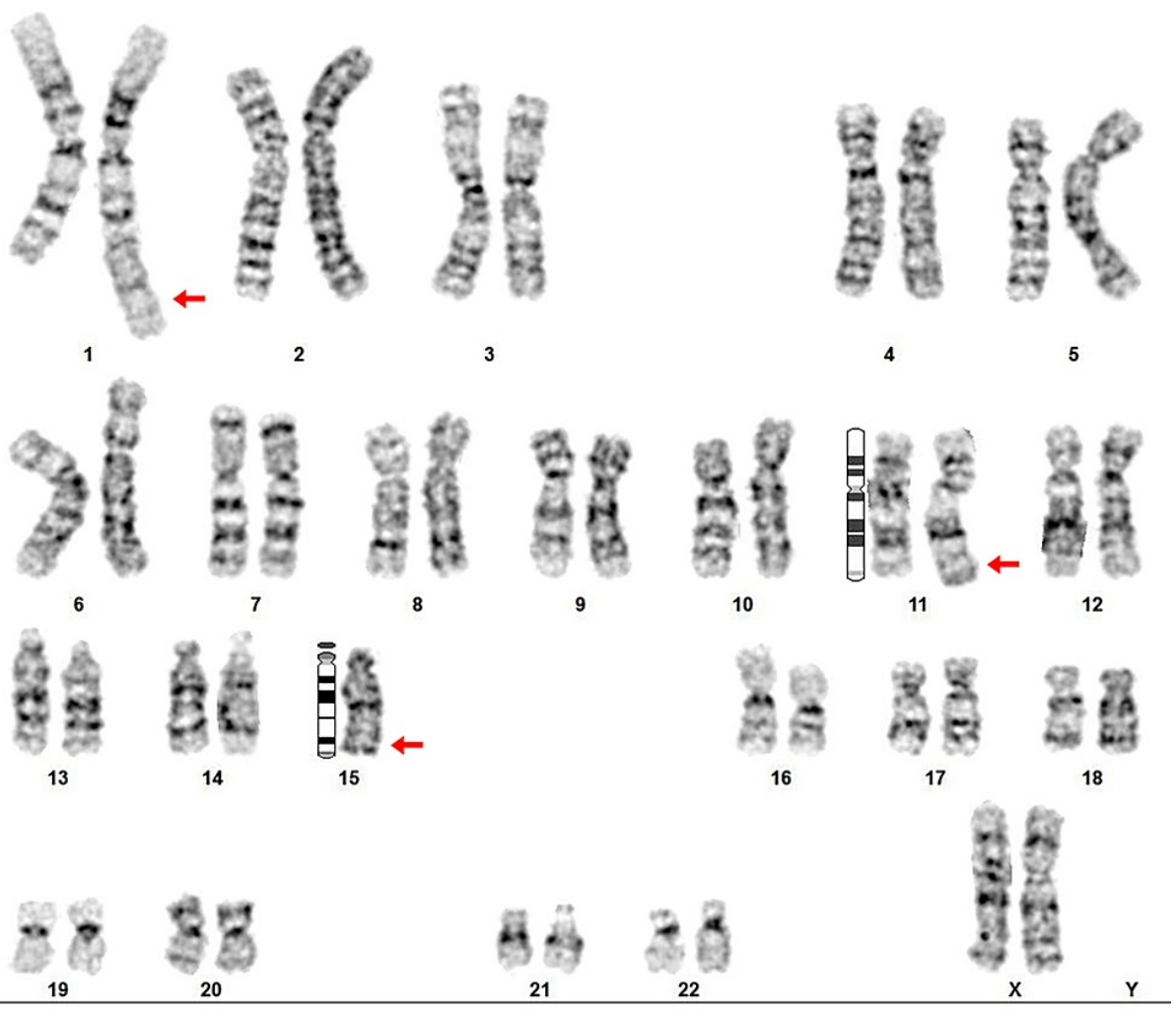

FIGURE 3: Complex chromosomal rearrangement in proband's mother. G-banding method at $\mathbf{7 5 0}$ bands per haploid on $\mathbf{5 0}$ spreads was performed.

As shown in figure 3, the most probable karyotype result of the mother could be 45, XX, ins (1::15) $(\mathrm{q} 42 ; \mathrm{q} 11.1 \rightarrow \mathrm{qter}), \mathrm{t}(1 ; 11)(\mathrm{q} 42, \mathrm{q} 25)$. According to chromosomal analysis of the mother, the proband inherited insertional fragment on chromosome number 11. Therefore, the proband's karyotype was 46, XY, ins (1::11) (q42 $\rightarrow$ qter::q25) compatible to partial trisomy 1 q $42 \rightarrow$ qter. According to normal G-banding chromosomal analysis of the maternal proband's family, the mother's karyotype was interpreted as a de novo balanced translocation.

\section{Discussion}

CCRs are structurally balanced or unbalanced aberrations involving more than two breakpoints on two or more chromosomes [9]. Chromosome rearrangements are more tolerated in female meiosis than male meiosis. Hence, approximately $75 \%$ of CCRs appear to be inherited maternally or are due to de novo rearrangements [10]. In the present case, karyotype analysis of the proband's parents revealed that CCRs originated maternally. The proband's mother, to our knowledge, is the first reported case of CCR with involvement of chromosomes $1,11,15$. The total number of breaks in this rearrangement were three involving non-reciprocal translocation containing the insertion of the 15q11qter region to $1 \mathrm{q} 42$ and 1q42qter region to 11q22 (Figure 4). The mother's translocation was de novo and no familial history of chromosomal abnormality were observed. This karyotype explained presence of infertility problems and abnormal offspring in this family. The mother's karyotype showed that derivative chromosomes could form a pentavalent structure in pachytene stage during meiosis I. The result of meiotic segregation in derivative chromosomes strongly depends on chromosome's feature in pentavalent configuration. The pentavalent and the relative synaptic regions are shown in a diagram (Figure 5). For present CCRs, the theoretical modes of meiotic segregation are 2:3 (the only mode of segregation can result in normal/balanced gametes), 4:1 and 5:0 that leading to produce 32 different gametes. The possibility of normal gametes or balanced translocation is very low. A theoretical prediction of chromosomal segregation in gametes expected that only $6.25 \%$ of gametes would be normal or balanced translocation. Thus, early pregnancy loss, infertility and abnormal offspring are very likely. 


\section{Cureus}

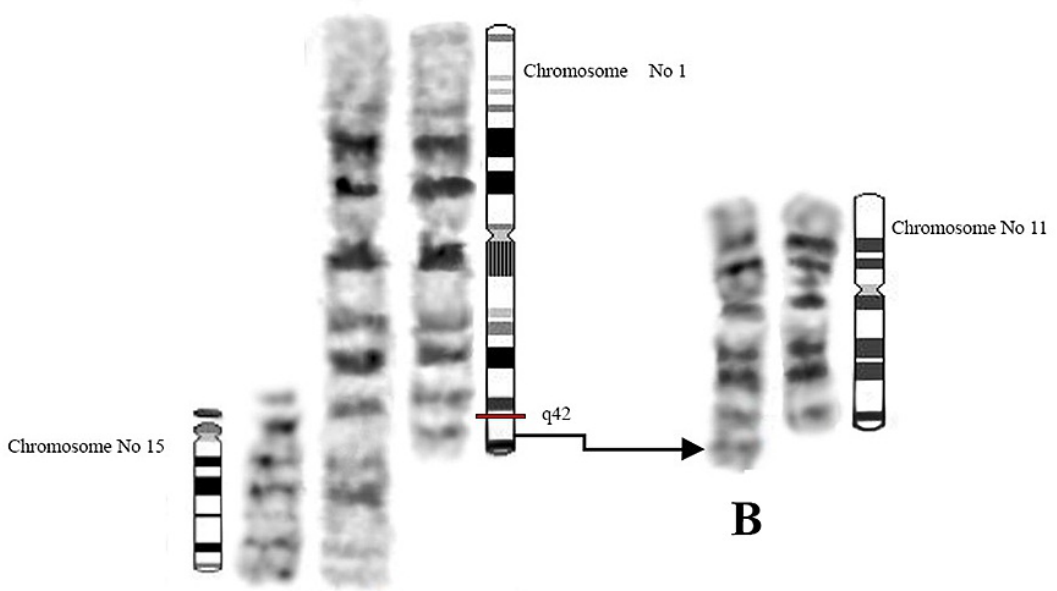

A

FIGURE 4: The translocations among three chromosomes in the mother of the proband.

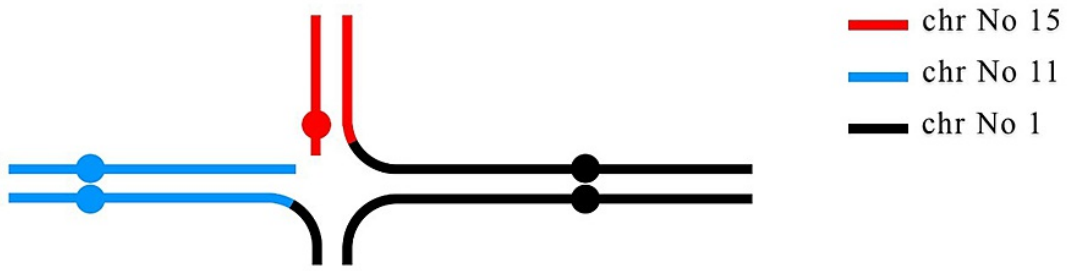

FIGURE 5: Theoretical pentavalent pachytene configuration adopted at meiosis I in the mother.

Figure 6 shows all possible gametes in 2:3 mode of segregation. Normal or balance translocated gametes and proband haploid with an extra segment on chromosome 11 are generated by 2:3 segregation. 


\section{Cureus}

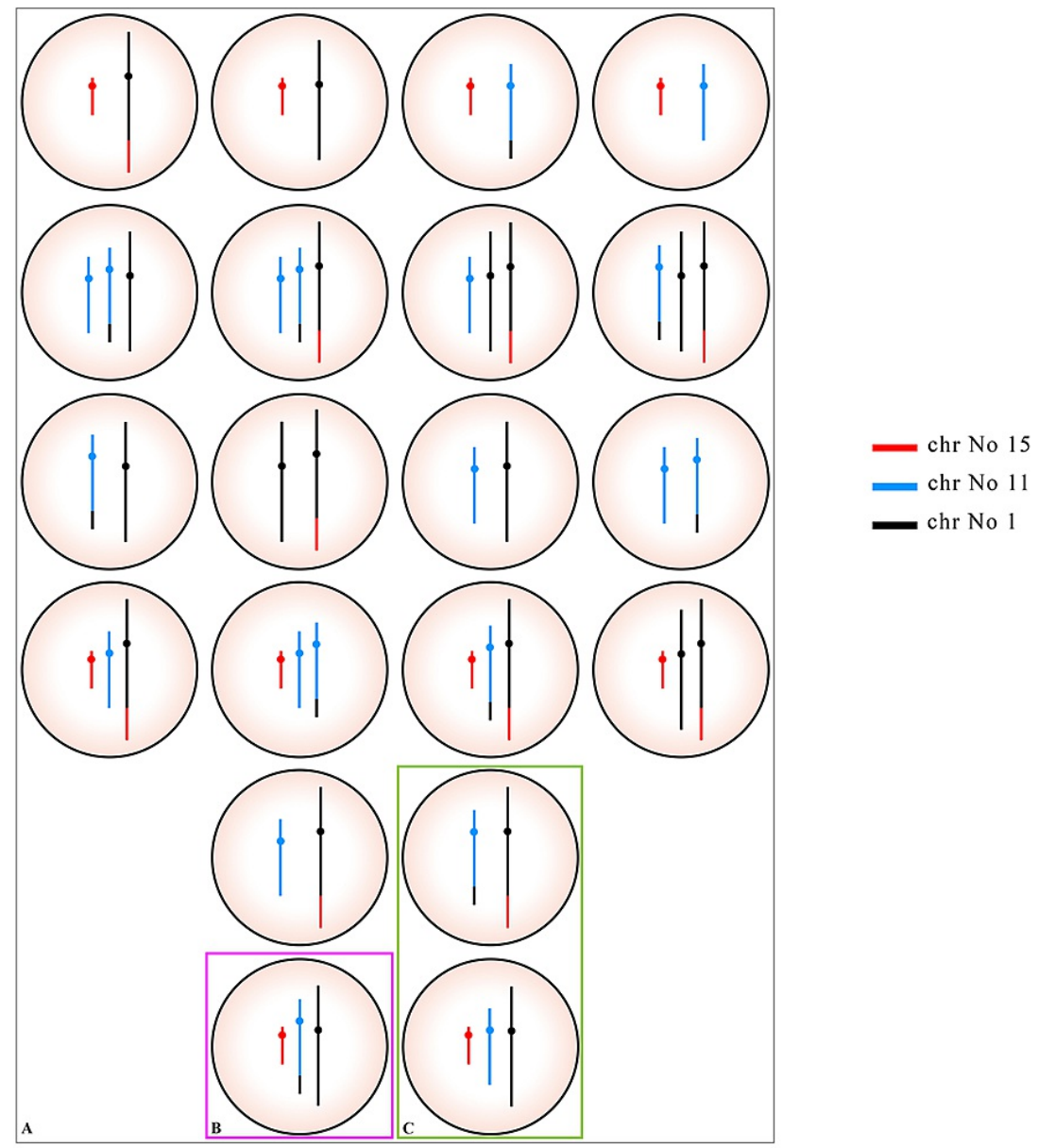

FIGURE 6: (A) Possible karyotypes of oocytes in mother through 2:3 segregation. (B) Segregation mode of the proband haploid. (C) Balanced haploid or normal complement.

Proband was detected with partial trisomy $1 \mathrm{q}$ which is a relatively common form of heredity autosome trisomy [11-13]. Partial 1q trisomy syndrome is considered a rare disorder which can be classified according to breakpoint position as $1 \mathrm{q} 32 \rightarrow \mathrm{qter}$ or $1 \mathrm{q} 42 \rightarrow \mathrm{qter}$. According to literature, partial trisomy of $1 \mathrm{q}$ without any other involving chromosomes often led to relatively mild phenotype which include macrocephaly, intellectual disability, developmental delay, triangular face and prominent forehead [11, 14, 15]. Cleft lip $[16,17]$ and inguinal hernia $[18,19]$ are rare symptoms that have been presented in few cases. When comparing the proband's clinical features described here with those reported cases that involve pure partial trisomy $1 \mathrm{q} 42 \rightarrow \mathrm{qter}$ syndrome, phenotypic similarities observed. According to the minimum involvement of chromosome 11q, in only the distal telemetric region, it can be concluded that the proband was affected by pure partial trisomy $1 \mathrm{q} 42 \rightarrow \mathrm{qter}$.

Linking chromosome segmented duplication abnormalities and clinical phenotypes is a challenging process due to presence of various modulation factors such as gene-dosage effect, gene-gene interactions, modified gene effect, chromosome position effect and epigenetic influences. Some genetic factors such as difference in the size of translocated segment, the number of involved chromosomes, underlying breakpoint and nongenetic factors including age, sex and environment make genetic counseling very difficult for families with CCR $[7,20]$.

\section{Conclusions}

In summery we present a de novo case of CCR with history of infertility, recurrent abortion and abnormal offspring. According to high risk of chromosomal abnormality in produced gametes, IVF-PGD (in vitro fertilization pre-implantation genetic diagnosis) using Array-CGH technique can be the best choice for this case. 


\section{Additional Information \\ Disclosures}

Human subjects: Consent was obtained or waived by all participants in this study. Conflicts of interest: In compliance with the ICMJE uniform disclosure form, all authors declare the following: Payment/services info: All authors have declared that no financial support was received from any organization for the submitted work. Financial relationships: All authors have declared that they have no financial relationships at present or within the previous three years with any organizations that might have an interest in the submitted work. Other relationships: All authors have declared that there are no other relationships or activities that could appear to have influenced the submitted work.

\section{Acknowledgements}

The Genetic Foundation of Khorasan Razavi supported this work.

\section{References}

1. Pellestor F, Anahory T, Lefort G, Puechberty J, Liehr T, Hédon B, Sarda P: Complex chromosomal rearrangements: origin and meiotic behavior. Hum Reprod Update. 2011, 17:476-94. 10.1093/humupd/dmr010

2. Trpchevska N, Dimova I, Arabadji T, et al.: A family study of complex chromosome rearrangement involving chromosomes 1, 8, and 11 and its reproductive consequences. J Assist Reprod Genet. 2017, 34:659-69. 10.1007/s10815-017-0893-7

3. Madan K: Balanced complex chromosome rearrangements: reproductive aspects. A review. Am J Med Genet A. 2012, 158A:947-63. 10.1002/ajmg.a.35220

4. Liao Y, Wang L, Zhang D, Liu C: Identification of a balanced complex chromosomal rearrangement involving chromosomes 3, 18 and 21 with recurrent abortion: case report. Mol Cytogenet. 2014, 7:39. 10.1186/17558166-7-39

5. Lazarczyk E, Drozniewska M, Pasinska M, Stasiewicz-Jarocka B, Midro AT, Haus O: Complex balanced chromosomal translocation $\mathrm{t}(2 ; 5 ; 13)(\mathrm{p} 21 ; \mathrm{p} 15 ; \mathrm{q} 22)$ in a woman with four reproductive failures. Mol Cytogenet. 2014, 7:83. 10.1186/s13039-014-0083-6

6. Courtens W, Vroman S, Vandenhove J, Wiedemann U, Schinzel A: Pre- and perinatal findings in partial trisomy 7q resulting from balanced parental translocations $t(7 ; 21)$ and $t(4 ; 7)$. Prenat Diagn. 2001, 21:642-8. 10.1002/pd.30

7. Shin YB, Nam SO, Seo EJ, et al.: Partial trisomy 1q41 syndrome delineated by whole genomic array comparative genome hybridization. J Korean Med Sci. 2008, 23:1097-101. 10.3346/jkms.2008.23.6.1097

8. Akalin I, Bozdag S, Spielmann M, Basaran SY, Nanda I, Klopocki E: Partial trisomy 1q41-qter and partial trisomy 9pter-9q21.32 in a newborn infant: an array CGH analysis and review. Am J Med Genet A. 2014, 164A:490-4. 10.1002/ajmg.a.36278

9. Kim JW, Chang EM, Song SH, Park SH, Yoon TK, Shim SH: Complex chromosomal rearrangements in infertile males: complexity of rearrangement affects spermatogenesis. Fertil Steril. 2011, 95:349-352.e5. 10.1016/j.fertnstert.2010.08.014

10. Kochhar PK, Ghosh P: Reproductive outcome of couples with recurrent miscarriage and balanced chromosomal abnormalities. J Obstet Gynaecol Res. 2013, 39:113-20. 10.1111/j.1447-0756.2012.01905.x

11. Chen C, Lin S, Su Y, Chern S, Su J, Lee C, Wang W: Partial trisomy 1q (1q42. 13--> qter) and partial monosomy 6q (6q27--> qter) in a girl with single median maxillary central incisor, corpus callosum dysgenesis and developmental delay. Genetic Counseling (Geneva, Switzerland. 2012, 23:447-455.

12. Watanabe S, Shimizu K, Ohashi H, et al.: Detailed analysis of 26 cases of 1q partial duplication/triplication syndrome. Am J Med Genet A. 2016, 170:908-17. 10.1002/ajmg.a.37496

13. Chia N, Bousfield L, Poon C, Trudinger B: Trisomy (1q)(q42 $\rightarrow$ qter): confirmation of a syndrome. Clinical genetics. 1988, 34:224-229. 10.1111/j.1399-0004.1988.tb02869.x

14. Kulikowski LD, Bellucco FT, Nogueira SI, et al.: Pure duplication 1q41-qter: further delineation of trisomy 1q syndromes. Am J Med Genet A. 2008, 146A:2663-7. 10.1002/ajmg.a.32510

15. De Brasi D, Rossi E, Giglio S, et al.: Inv dup del (1)(pter--\&gt;q44::q44-- \&gt;q42:) with the classical phenotype of trisomy 1q42-qter. Am J Med Genet. 2001, 104A:127-30. 10.1002/ajmg.1589

16. Utine GE, Aktas D, Alanay Y, Gücer S, Tuncbilek E, Mrasek K, Liehr T: Distal partial trisomy 1q: report of two cases and a review of the literature. Prenat Diagn. 2007, 27:865-71. 10.1002/pd.1788

17. Kímya Y, Yakut T, Egelí U, Ozerkan K: Prenatal diagnosis of a fetus with pure partial trisomy 1q32-44 due to a familial balanced rearrangement. Prenat Diagn. 2002, 22:957-61. 10.1002/pd.403

18. Tartaglia E, Mastrantonio P, Costa D, Giugliano B, Porcellini A, Costagliola C: Trisomy 1q42-qter associated with monosomy 6q27-qter: a case report. Eur J Ophthalmol. 2011, 21:315-9. 10.5301/EJO.2010.5796

19. Chen CP, Lin SP, Su YN, Chern SR, Su JW, Lee CC, Wang W: Partial trisomy 1q (1q42.13--\&gt;qter) and partial monosomy 6q (6q27--\&gt; qter) in a girl with single median maxillary central incisor, corpus callosum dysgenesis and developmental delay. Genet Couns. 2012, 23:447-55.

20. DuPont BR, Huff RW, Ridgway LE, Stratton RF, Moore CM: Prenatal diagnosis of partial trisomy 1q using fluorescent in situ hybridization. Am J Med Genet. 1994, 50:21-7. 10.1002/ajmg.1320500105 